\title{
Use of laser-scanner as an intervention tool in fortifications: Santa Barbara Castle in Alicante
}

\author{
V. Echarri Iribarrena ${ }^{1}$, M. I. Pérez Millán ${ }^{2}$, A. González Avilés ${ }^{2}$, \\ J. Garabito López ${ }^{2} \&$ A. Priego Valladares ${ }^{1}$ \\ ${ }^{I}$ Department of Building Construction, University of Alicante, Spain \\ ${ }^{2}$ Department of Building Construction, University of Burgos, Spain
}

\begin{abstract}
The laser-scanner is a considerably useful and effective tool in Heritage intervention projects. It is particularly outstanding in buildings with highly complex geometry or great scale. Such is the case of bastioned fortifications, because these buildings have usually undergone continual alterations and additions throughout their history. Santa Barbara Castle is one of the most important fortified complexes of the Spanish Mediterranean coast. It is situated in a strategic location in the city of Alicante. The fortified bastion contains several bastioned fronts and many buildings inside. During the years 2007 and 2008, a research team composed of members from the University of Alicante and the University of Burgos developed a study on the conservation status of the castle. This study was funded through research grants from the Generalitat Valenciana (Project GV reference 2007/150), and an agreement with Manuel Peláez Foundation. We have generated a 3D object of the complex through laser scanner in order to manage the analysis of the conservation status. This tool reduced greatly the architectural survey work, providing extremely accurate plans. Through hyperlinks we were able to associate the 3D elements to old and current photographs, to the details of historical cartography, to microscopy images of mineralogical analysis and to the graphical representation of pathologies as well. Thus we have immediate access to the information on each element of the castle using the program Pointools View with a simple click on each 3D element. This technique has meant better accuracy in the study of conservation status and has greatly reduced the required time.
\end{abstract}

Keywords: laser-scanner, Alicante, castle, document management. 


\section{Introduction}

Projected interventions into complex bastioned fortifications complexes require difficult specialist surveying techniques and numerous field visits. It is required to collect systematically information about the status of the stone facings, linings, foundations etc. Previous studies usually contain abundant graphic and written documents that allow a thorough knowledge of the construction techniques used and the evolution of buildings throughout history. We have to generate numerous images, the characterization of the stone, mortar and other materials, and mineralogical analysis in order to determine the pathologies suffered by the building. Once we have determined the pathologies suffered by the architectural complex, we must depict graphically in a document each one of these lesions with appropriate symbols, specifying stone by stone and area by area precisely where the damage lies. Then we carry out accurate measurements in order to evaluate the budget and to establish the proper planning of work.

Photogrammetry has been widely used to generate three-dimensional models by taking pictures of architectural elements. This technique is shown as a useful tool to represent geometrically well-defined forms, but it is unfeasible to deal with the complex geometry shapes (Salonia et al. [1] and Massimiliano et al. [2]).

The laser scanner is presented as an alternative or complement to photogrammetric techniques. It carries out the generation of 3D models and the survey more quickly and accurately (Pavlidis et al. [3]). The building is automatically scanned with the resolution required within the equipment limits. The data collection can usually get 1,500 points per second with their respective coordinates $(\mathrm{X}, \mathrm{Y}, \mathrm{Z})$ with respect to the laser-scanner location. This speed can be even increased. Each point has assigned coordinates $(R, G, B)$ by projecting their geometric coordinates to a colour imaging device that is coupled internal or externally to the scanner, following the model in projected perspective. A cloud of points is generated for each laser-scanner shot. All the shots can be processed together by taking a few references to overlap the different shots, getting a 3D object consisting of a point cloud. It is possible to incorporate colour to this object, with the limitations of light that incises in each one of the shots, and taking into account that initially it does not apply colour to the interstices between points. We can generate a polygon model through processes of triangulation points, so we obtain a mesh that conforms fairly close to the surfaces of the architectural element (Armesto et al. [4]).

This paper describes the methodology applied to Santa Barbara Castle in Alicante to carry out a study about its conservation state, with the development of mineralogical characterization reports, graphical representation of pathologies, and the use of the 3D object generated by laser-scanner as a management tool, through hyperlinks associated with the different architectural elements of the fortified complex. 


\section{Historical background}

Santa Barbara Castle is one of the most important fortified complexes of the Spanish Mediterranean coast. It is located in a strategic location on a rocky promontory that overlooks the coast. It was transformed over the centuries to become the main fortress of the Alicante coast. Its first traces are from the period of Muslim rule, although archaeological work is being carried out nowadays in order to determine its origins with more precision. After the significant development experienced by Muslim masters, and the subsequent changes in the Christian Middle Ages, it suffered a major transformation in the late sixteenth century, when Philip II appointed the most prestigious military engineers of the time to carry out a modernization project of the castle. Military engineers Fratín and Vespasian Gonzaga planned and directed the works of the castle's north eastern part, designing a bastioned front, so the fortified complex included most of the Muslim areas that were allocated to store the crops and guard the cattle: the Albacar den Mig and the lower Albacar.

At the end of the seventeenth century other transformations were motivated by the war with France. Demolition of the top of the medieval towers of el Macho commenced and a new wall was constructed around them. British troops under the command of Generals Gorges and Richards executed major reforms during the War of Succession. Underneath the bastioned front of Fratín an outer curtain and two low bastions were built, which reinforced the front most useful against attack, making an effective echeloned defence. The castle suffered the effects of a mine during the War of Succession in 1709 by felipistas troops under General D'Asfeld, which caused the collapse of a bastion and the rupture of the higher cistern. This southern front of the castle, near the area of the Macho, was transformed with a curtain, but the bastion was not rebuilt because the rock on which it was built had been eliminated.

Since then and until nowadays no changes had taken place in the fortified complex, just a few buildings inside, such as the headquarters of Philip II, or the church of Santa Barbara. It was then the castle adopted that denomination.

\section{Study of the conservation status of the Santa Barbara Castle in Alicante}

The research group "Technology and Sustainability in Architecture" has recently completed a study on the conservation status of the Santa Bárbara Castle, Alicante. The multidisciplinary research team has members from the Universities of Alicante and Burgos. The study was funded through grants from the Generalitat Valenciana (Project GV reference 2007/150) and an agreement with Manuel Pelaez Foundation.

We have produced several documents in order to provide preliminary studies to the City Council of Alicante for the future conservation interventions in this complex, because it is a reference for military construction in Eastern Spain. First of all, it is a comprehensive historical and constructive research, which draws on various projects carried out by military engineers throughout its 
consulted more than twenty archives. We have collected over two hundred historical maps in a chronological order catalogue. We have provided notes on the historical importance and the elements that were built after each one of these projects, in addition to the information about authorship, date, scale, representation techniques, etc.

After dissecting the architectural complex in more than 250 elements with reference to the fronts to which they belong, we took over 7,000 photographs of the current state, to provide a tool to carry out the mapping of the damages more efficiently.

The surveying was done through the use of laser scanner. As we discussed below, it was a major breakthrough by saving time and adding value through the precision laser surveys provide. Over 35 elevation drawings were developed to represent as closely as possible the damages detected and analyzed in the complex: dirt, stone weathering, vegetation, biological surface soiling such as lichens and moss, rubefaction, metallic staining, loss of grouting mortars, coating detachments, cracks, partial loss of ashlars and masonry and efflorescence. These documents mapping the pathologies were completed with excel tables to quantify the damages detected, in meters or square meters. This makes possible to perform preliminary measurements of intervention and global budgets, serving as a reference when you draw up the working projects for each one of the parts of the castle. Also they can be used as guide by the City Council of Alicante when planning interventions.

The last document contained the mineralogical analysis of the stones and mortars of the various walls and masonry works of the castle. For this reason we tested thirty specimens from various existing walls selecting them by origin and age. Then, they were analyzed by optical microscopy techniques of transmitted light and X-ray diffraction (XRD). The transmitted light microscopy has been used to the petrographic study with polarized light of ten thin sheets of rock. The thin sheets were taken by the Sample Preparation Service of the Department of Petrology and Geochemistry of the Universidad Complutense in Madrid. Third of the preparation was stained, with alizarin red (to differentiate calcite and dolomite) and potassium ferrocyanide (to distinguish ferrous carbonate minerals of non-ferrous). The petrographic microscopes that were used for this study were the Carl Zeiss Standard W. L. and the Nikon E600 POL. photomicroscope. This latter served for the realization of the photographs as well. This analytical technique allows knowing what are the mineralogy, texture and rocks classification, and the approximate percentages of its components.

$\mathrm{X}$-ray diffraction (XRD) is used to identify crystalline phases present in the stone material analyzed. Disoriented powder was used, that was obtained after milling the rock to a size below $0.04 \mathrm{~mm}$. The equipment used was a Siemens D 5000 diffractometer, with a program for automatic identification of phases supported by a database-PDF2 JPDS. This database has 137,000 patterns of reference crystalline phases (mineral sub base with 15,800 patterns). $\mathrm{K \alpha} \mathrm{Cu}$ radiation was used, graphite monochromator, a potential difference in the tube of $40 \mathrm{kV}$ and $20 \mathrm{~mA}$ intensity in the filament; the analysis has been performed in the range $2 \theta: 2-60^{\circ}$. 


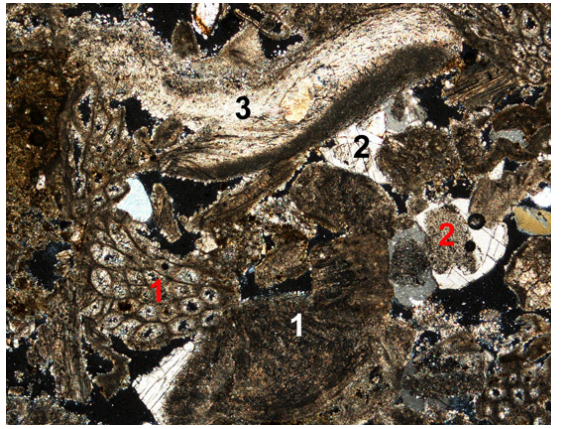

Figure 1: General microscopic appearance where there are fragments of bryozoans (1), echinoderm plates (2) and fragments of ostreids (3).

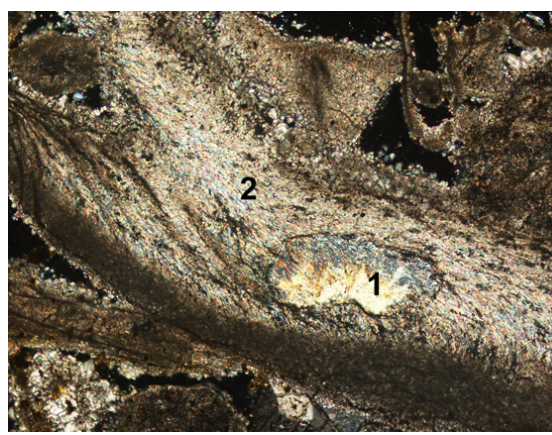

Figure 3: $\quad$ Partial silicification (1) of a fragment of bivalve ostreids (2).

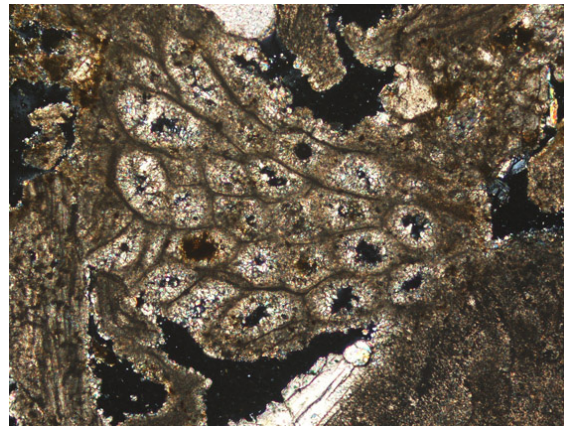

Figure 2: Detail of bryozoan with zooecias filled with sparite.

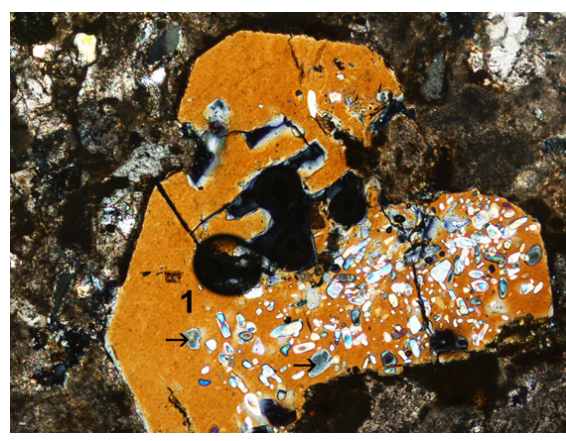

Figure 4: Detail of an authigenic quartz grain (1) with abundant vacuolar inclusions (arrows).

\section{Generating the 3D object through laser-scanner}

The topographic and volumetric surveying was made through the use of laserscanner. This provides much more information than the photogrammetric method, moreover, the field work is drastically reduced. Photogrammetry techniques require considerable effort in the work of data collection. It takes several weeks to reference a few hundred points, from which it's possible to generate the perspectives of the building that can be improved with photographs, 


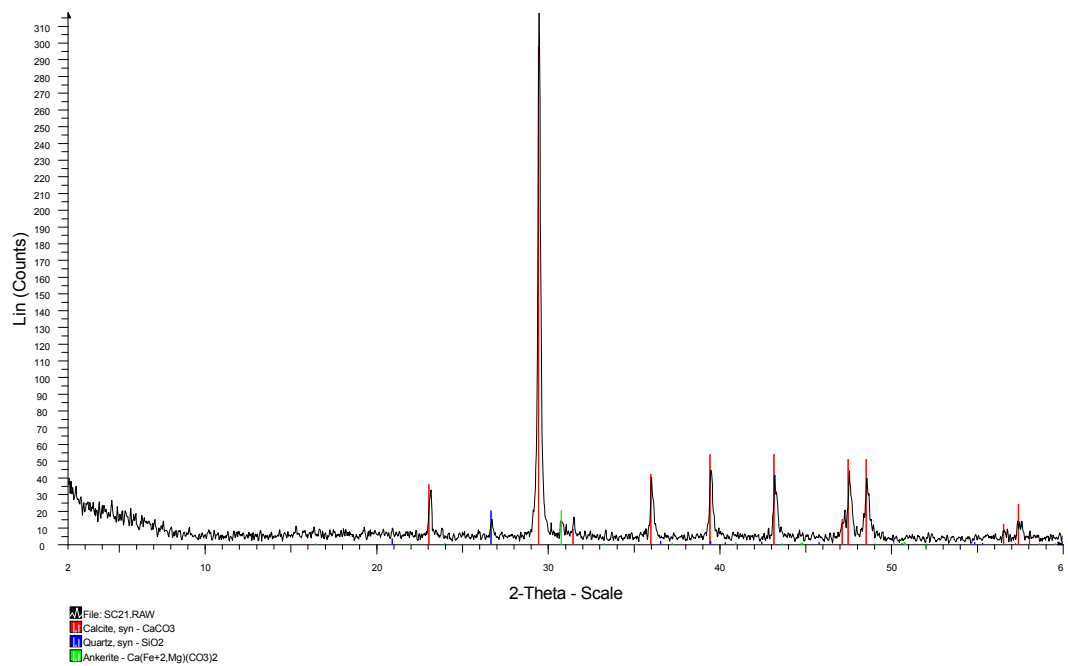

Figure 5: $\quad$ Diffractogram of the sample TSC 21.

Table 1: $\quad$ Summary table of results: diffractograms of $50 \%$ of the samples.

\begin{tabular}{|c|c|c|c|c|c|c|}
\hline \multirow[b]{2}{*}{ Sample } & \multicolumn{6}{|c|}{ Contents } \\
\hline & $\begin{array}{l}\text { Calcite } \\
\mathrm{CaCO}_{3}\end{array}$ & $\begin{array}{c}\text { Dolomite } \\
\text { CaMg } \\
\left(\mathrm{CO}_{3}\right)_{2} \\
\end{array}$ & $\begin{array}{c}\text { Quartz } \\
\mathrm{SiO}_{2}\end{array}$ & $\begin{array}{l}\text { Lime } \\
\mathrm{CaO}\end{array}$ & $\begin{array}{l}\text { Halite } \\
\mathrm{NaCl}\end{array}$ & $\begin{array}{c}\text { Plaster } \\
\mathrm{CaSO}_{4} 2 \\
\mathrm{H}_{2} \mathrm{O}\end{array}$ \\
\hline Albacar $\mathrm{N}^{\circ} 1$ & 69,8 & & 5,6 & 6,8 & 1,9 & 15,9 \\
\hline Albacar $\mathrm{N}^{\circ} 3$ & 93,4 & 5 & 1,6 & & & \\
\hline Albacar $\mathrm{N}^{\circ} 5$ & 75,7 & & 7,1 & & & 17,2 \\
\hline Albacar Vell No 4 & 84,7 & & 4,1 & & & 11,2 \\
\hline Albacar Vell Nº 21 & 73,7 & 14,7 & 9,5 & & 2,1 & \\
\hline St. Jordi's tower $\mathrm{N}^{\mathrm{o}} 16$ & 79,4 & 7,9 & 12,7 & & & \\
\hline St. Jordi's tower $\mathrm{N}^{\mathrm{o}} 18$ & 88,6 & & 4,7 & & 2,5 & 4,2 \\
\hline Ravelin new No 19 & 83,5 & 7,3 & 2 & 2,4 & 0,8 & \\
\hline Ravelin new No 20 & 87,8 & 3,1 & 3,1 & & & 6 \\
\hline Bastion of St. Anne $\mathrm{N}^{\circ} 22$ & 87,3 & & 4,5 & & & 8,2 \\
\hline Bastion of St. Anne $\mathrm{N}^{\circ} 23$ & 82,8 & 11,8 & 4,2 & & 1,2 & \\
\hline Queen's bastion No 24 & 94,5 & & 4,8 & & 0,7 & \\
\hline Queen's bastion $N^{\circ} 25$ & 68.1 & & 10 & & 10,2 & 11,8 \\
\hline St. Catherine's tower $\mathrm{N}^{\circ} 11$ & 72,7 & & 9,4 & & 8,5 & 9,4 \\
\hline St. Catherine's tower $\mathrm{N}^{\circ} 13$ & 85,4 & & 5,1 & & 9,5 & \\
\hline
\end{tabular}

and adjusting and coordinating the points with which it was obtained the coordinates in reference lines (Lisinger [5]).

The laser-scanning technique differs radically from the previous one. The generated point clouds are adequately treated to liberate them from the noise produced. After this, we overlap them properly according to coordinates (X, Y, $\mathrm{Z})$ of some points. Later we treat them through software such as Rapidform, Geomagic Studio or Polyworks. In the data collection carried out in the various 
laser scanner shots we find gaps - those elements to which the laser does not have access - as well as redundant or duplicate points, which must be treated in this second phase. We solve the adjustment of data through algorithms in order to adjust the points in the gaps. Every software program has its own algorithms to solve such problems. Good planning of scanner positions significantly minimizes these problems.

Through the software we can generate clouds of points with different resolutions like a filter, selecting points within a certain maximum distance, for example $2 \mathrm{cms}$, thus a better distribution of the resolution, since the laser scanner obtains more density of points in those elements that are closer and less on those further away. These clouds of points are generated depending on the resolution at which you want to work and the equipment available. They can be treated with software such as Pointools View 1.7 Pro or the version available for CAD, to proceed to use them in the representation of detected and analyzed damages in the architectural complex, or in the management of the information associated with the $3 \mathrm{D}$ object.

This is how it has been done in the present example, Santa Bárbara Castle. First of all, it was the planning of the positions in which a priori the laser scanner would be located. It was impossible to place the laser-scanner in some of the roofs because of the security and the accessibility issues. We used a laser scanner Riegl LMS-Z420i for the data collection. The work was done in two phases: in the first phase we took 120 shots and 60 in the second one, because it was required due to the magnitude of this fortified complex as well as the complexity of its architecture. In some elements, such as coronations of parapets or portholes, it could not be obtained point clouds. We did not take shots inside the buildings. The clouds of points in the second phase were treated as described above, generating a cloud of points spaced every $2 \mathrm{~cm}$ of $700 \mathrm{Mb}$ size (Bruno et al. [6]). Later, we employed the program Pointools View 1.7 Pro to generate plans and general elevations, and plans and elevations of details of the various buildings and architectural elements of the castle (Fig. 6).

Given that in the year 2001 it was carried out the castle surveying through traditional techniques, and that we used the laser-scanner three years ago, we can establish that the traditional system spent twelve weeks of work between data collection and delineation in the studio, while this work was done in just three weeks with the technique of laser-scanner. In addition, given the geometric complexity of the castle, with significant level differences between the elements and buildings, it is clear that in no case could do a complete surveying of the castle but only the most relevant parts. So, this would involve a very long time if we wanted to do with some minor elements, while through the $3 \mathrm{D}$ object and suitable software this task could be done in just one day. We generated a total of 35 rectified elevation plans in $2 \mathrm{D}$ to be used for representing graphically with the appropriate symbols the pathological processes detected in the walls and the architectural elements of the castle (Echarri et al. [7]). 


\section{Use of the 3D object as a management tool}

One of the most complex aspects of this type of research is the management of the generated documentation, graphic and written, in each one of its phases, its

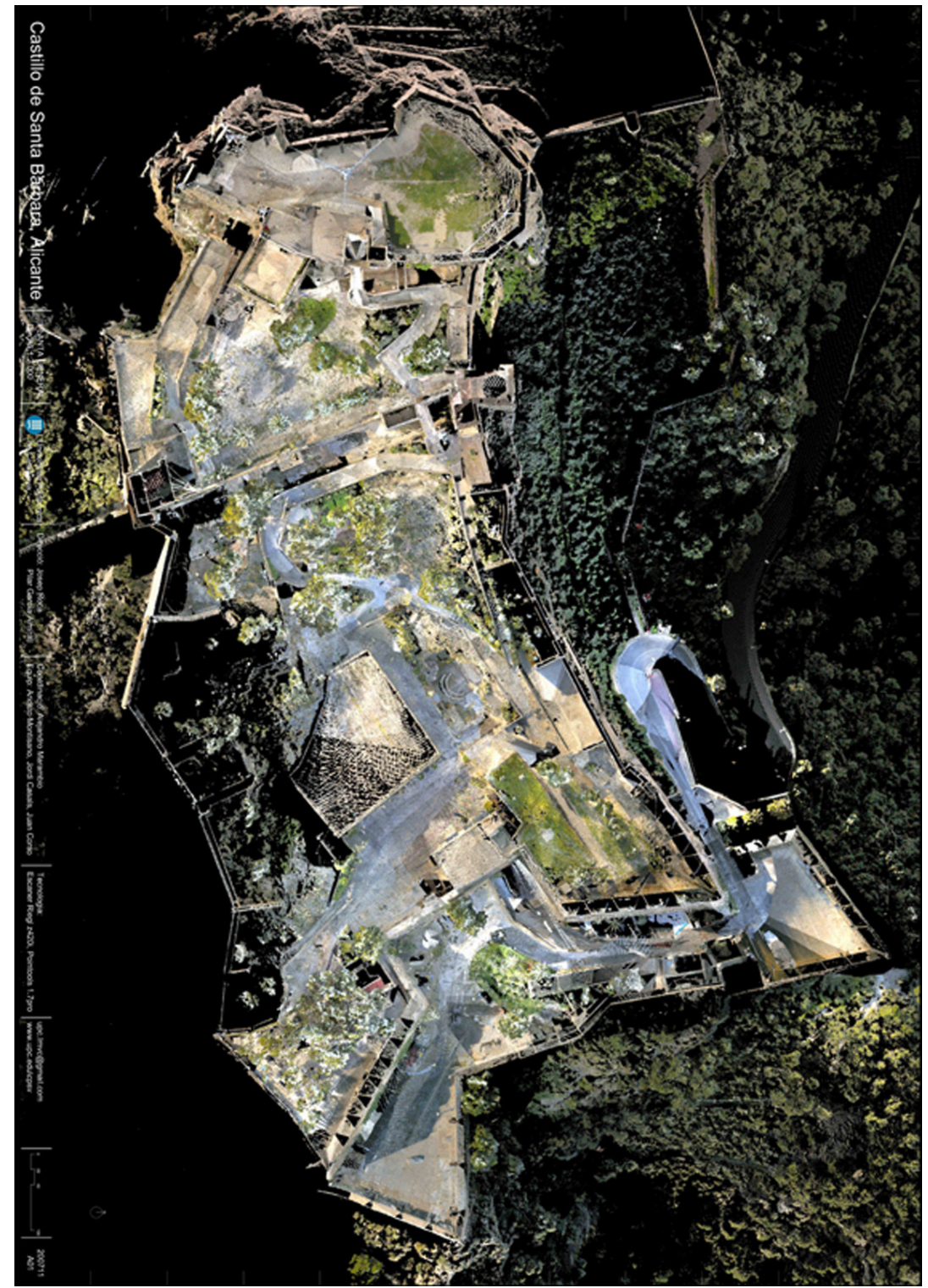

Figure 6: $\quad$ Plant of the generated 3D object. 

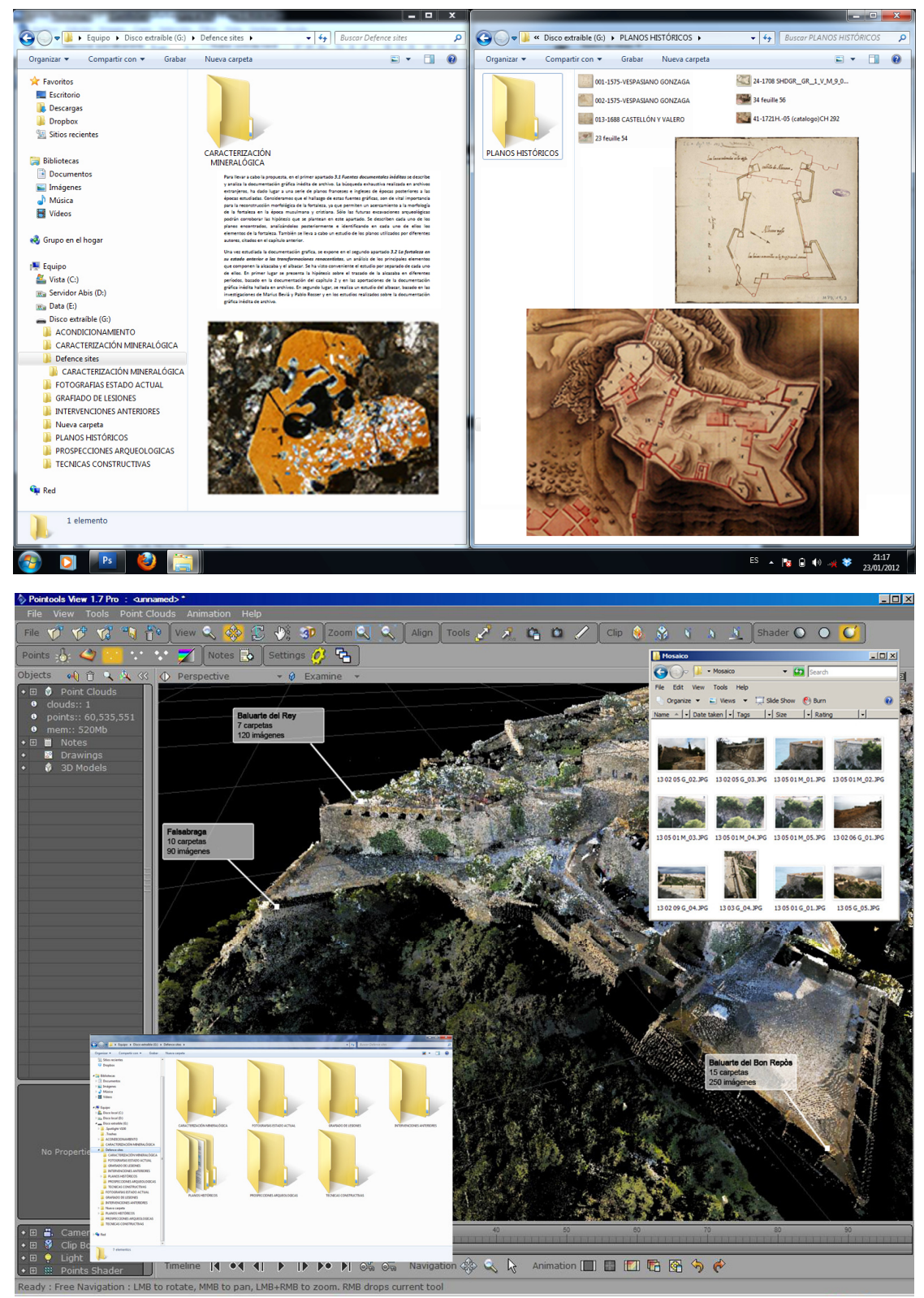

Figure 7: Display of the two computer screens with hyperlinks.

structure, interrelation and ease of search by the authors of the reports and documents as well as technicians of public administrations in future years. The ideal is to create a tool that allows all these aspects in an efficient and convenient for users even for those not involved in its genesis. Also must be able to continue 
incorporating other information, analysis or reports in the future. The information generated in each of the documents is enormous, both in terms of the number of scanned files and in the memory they occupy. This requires computer tools with high-capacity of RAM and adequate graphics cards.

The program Pointools View Pro 1.7 allows us to establish hyperlinks between other scanned files and any point from the generated cloud of 3D object. From the beginning, we proceeded to experiment with the possibility of hanging in the $3 \mathrm{D}$ object all the information that would be generated over the three-year research process. We studied the organization that should be adopted in this process, through main folders, secondary folders and subfolders, so we established a menu for each one of the elements that we had divided the buildings of the castle. From this menu of each one of the 250 elements, we can access to the following information:

1. Photographs of current condition. In total more than 7,000.

2. Details of historical cartography preserved in archives. More than 200 drawings preserved in 10 European and Spanish archives.

3. Relevant transcribed documents from the period.

4. Construction techniques used in the item.

5. Mineralogical characterization of stone and mortar walls constituting the architectural element.

6. Mapping of damages detected in all parts of that element, shown in elevation plans.

7. Tables of measurements of each one of the detected pathologies.

Immediate access to all information generated about each element represented a significant saving in time of drafting the conservation status reports, mainly in mapping the pathological processes. While in the working phase of year 2001 this task spent the working time of a person for a full year, through this method of work with the access to the photographical information and building techniques produced the same result in a three months time, besides, costs were greatly reduced while providing greater accuracy in representing graphically and a more reliable outcome.

The 3D object obtained by laser scanning has become an excellent tool for information management [8]. Besides, the City Council of Alicante will be able to introduce the information of future reports and actions in the heritage. It may also be useful for creating an object accessible through the network with some of the information generated in the project, in which internauts can learn in greater depth the history and heritage value of the castle. The castle has great tourist potential, which could be increased by this tool of easy access and management.

\section{Conclusions}

The use of laser scanning technique is shown as very appropriate tool for intervention projects in military fortifications, especially when dealing with a fortification complicated because of its geometry, volume and fragmentation.

Through programs like Pointools View Pro 1.7 can be represented the damages of each element in a manner more efficient, more dynamic and faster, 
simply by creating hyperlinks in each item. The experience in the work of mapping the pathologies revealed a significant savings in time spent, around $75 \%$ compared to traditional systems.

This software allows converting the $3 \mathrm{D}$ object into a tool for information management. This way you can have immediate access to the intervention record of each architectural element, information of the characterization of stones and mortars, actual photographs of detail, historical maps and any other information. It's a tool with great cultural and tourist potential as it would allow access to the information that is deemed appropriate by the network.

\section{Acknowledgements}

The authors express sincere gratitude to the Generalitat Valenciana, through the Department of Education, to the Foundation Manuel Peláez, and to the Vicerrectorate of Research of the University of Alicante, who have made this research possible.

\section{References}

[1] Salonia, P. et al., Multi-scale cultural heritage survey: Quick digital photogrammetric systems. Journal of Cultural Heritage, v. 10 (2009) pp.e59-e64.

[2] Massimiliano P. et al., 3D digitizing of cultural heritage. Journal of Cultural Heritage, v. 2 (2001) pp.63-70.

[3] Pavlidis, G. et al., Methods for 3D digitization of Cultural Heritage. Journal of Cultural Heritage, v. 8 (2007) pp.93-98.

[4] Armesto, J. et al., Modelling masonry arches shape using terrestrial laser scanning data and nonparametric methods. Engineering Structures, v. 32 (2010) pp.607-615.

[5] Lisinger, S., 3D laser versus stereo photogrammetry for documentation and diagnosis of buildings and monuments (pro and contra) in: CIPA 2005, XX International Symposium, Torino (2005).

[6] Bruno, F. et al., From 3D reconstruction to virtual reality: A complete methodology for digital archaeological exhibition. Journal of Cultural Heritage, v. 11 (2010) pp.42-49.

[7] Echarri, V. et al., "Generating a 3D tool to represent graphically the damages of Santa Barbara castle (Alicante)". XXXVII IAHS World Congress on Housing Science. Santander (2010).

[8] Salonia, P. et al., Multi-scale cultural heritage survey: Quick digital photogrammetric systems. Journal of Cultural Heritage, v. 10S (2009) pp.e59-e64. 